\title{
Tyrosine-Protein Kinase ABL1
}

National Cancer Institute

\section{Source}

National Cancer Institute. Tyrosine-Protein Kinase ABL1. NCI Thesaurus. Code C17390.

Tyrosine-protein kinase ABL1 (1130 aa, $123 \mathrm{kDa}$ ) is encoded by the human ABL1 gene.

This protein is involved in tyrosine phosphorylation, signal transduction, cell motility, cell adhesion, receptor endocytosis, autophagy and apoptosis. 